\title{
Pulmonary function in extremely low birth weight infants with bronchopulmonary dysplasia before hospital discharge
}

\author{
Cindy T. McEvoy $\mathbb{D}^{1} \cdot$ Diane Schilling ${ }^{1} \cdot$ Mitzi D. Go ${ }^{1} \cdot$ Shawn Mehess ${ }^{2} \cdot$ Manuel Durand $\mathbb{D}^{3}$
}

Received: 30 May 2020 / Revised: 2 September 2020 / Accepted: 26 September 2020 / Published online: 11 October 2020

(c) The Author(s), under exclusive licence to Springer Nature America, Inc. 2020

\begin{abstract}
Objective To compare pulmonary function in extremely low birth weight (ELBW) infants with bronchopulmonary dysplasia (BPD) studied at 34-36 weeks postmenstrual age (PMA) with a reference group of "healthy" infants born at 34-36 weeks. We hypothesized that ELBW infants have decreased functional residual capacity (FRC) and respiratory compliance (Crs). Study design Pulmonary function testing was performed at 34-36 weeks PMA in infants with BPD and within $96 \mathrm{~h}$ of age in infants delivered at 34-36 weeks.

Results Twenty BPD patients and 20 healthy infants were studied. FRC (18.9 versus $26.2 \mathrm{~mL} / \mathrm{kg}$; adjusted 95\% CI 5.0, 10.9; $P<0.001)$ and $\mathrm{Crs}\left(0.80\right.$ versus $1.29-\mathrm{mL} / \mathrm{cm} \mathrm{H}_{2} \mathrm{O} / \mathrm{kg} ; 95 \%$ CI $\left.0.31,0.71 ; P<0.001\right)$ were decreased in BPD patients. Respiratory resistance was increased in BPD patients.

Conclusions ELBW infants with BPD have decreased pulmonary function compared to healthy infants delivered at 34-36 weeks. This suggests that infants with BPD have smaller lung volumes.
\end{abstract}

\section{Introduction}

Bronchopulmonary dysplasia (BPD) is a major adverse outcome of very premature delivery and is a product of the success of current neonatal intensive care. Lung development is a vulnerable highly orchestrated process that can be significantly affected by multiple factors particularly preterm delivery. The increased survival of extremely low birth weight (ELBW) infants has changed the pathology of BPD, from one of acute lung injury initially described in moderately premature infants born in the late saccular stage of lung development, who had been managed on high ventilator pressures and high oxygen resulting in inflammation, fibrosis, and smooth muscle hypertrophy in the airways, to one of disrupted lung development $[1,2]$. Contemporary BPD (new

Cindy T. McEvoy

mcevoyc@ohsu.edu

1 Division of Neonatology, Department of Pediatrics, Oregon Health \& Science University, Portland, OR, USA

2 Department of Psychology, Portland State University, Portland, OR, USA

3 Pediatrics, Keck School of Medicine, University of Southern California, Los Angeles, CA, USA
BPD) primarily occurs in ELBW infants (birth weight < $1000 \mathrm{~g}$ ), often without much lung disease after birth. They are delivered in the late canalicular to early saccular stages of lung development at a very early stage of the ongoing rapid increase in septation of the distal airspaces $[1,3]$.

The new BPD is a disease of prematurity with impaired alveolarization. Histologic studies have shown that infants dying of BPD in the surfactant era have lungs with fewer and larger alveoli with less fibrosis and inflammation than in the past. In preterm baboon models a decrease in total internal surface area has also been shown [4]. Despite intense research focus, there has been limited success in primary prevention of BPD possibly because it is primarily due to impaired alveolarization, a process which is still poorly understood [5]. There are also some very premature babies who do not develop BPD so enhanced definitions of BPD phenotypes are needed to help tailor future interventions.

There have been several reports of follow-up pulmonary function tests (PFTs) of postsurfactant BPD survivors showing these children continue to have abnormal baseline spirometry with significant airway obstruction [6, 7]. Interestingly, there are limited pulmonary function data in ELBW infants with BPD prior to discharge particularly in terms of comparison to a "healthy preterm lung" of comparable postmenstrual age. This information may help us better define the 
physiologic changes found in contemporary BPD and help identify different BPD phenotypes. It may also allow us to gain insights into the normal process of growth and development of the lung and monitor the course of lung disease.

We have previously reported altered pulmonary function in healthy preterm infants born at 33-36 weeks of gestation and studied at term-corrected age compared to healthy term infants [8]. As a group, these children progress to have increased wheezing and asthma. With the above in mind, the objective of this study was to compare the PFTs in ELBW infants with contemporary/postsurfactant BPD studied at 34-36 weeks postmenstrual age with a reference group of "healthy" infants born at 34-36 weeks. We hypothesized that the ELBW infants with BPD would have decreased functional residual capacity (FRC) and respiratory system compliance (Crs) compared to healthy infants born at 34-36 weeks.

\section{Methods}

\section{Eligibility criteria/study design}

This is a prospective cohort study done in the neonatal intensive care unit (NICU) at Oregon Health \& Science University, Portland, Oregon. The study was approved by the Institutional Review Board of our hospital, and informed consent was obtained from the parents. The inclusion criteria for the study group of patients with BPD included: (1) infants with a birth weight $<1000 \mathrm{~g}$; (2) need for oxygen supplementation at 36 weeks of postmenstrual age [1] to maintain a pulse oximeter oxygen saturation $\left(\mathrm{SpO}_{2}\right)>90 \%$; (3) studied with PFTs at 34-36 weeks postmenstrual age. Inclusion criteria for the comparison group (reference group) of healthy preterm infants were: (1) gestational age of 34-36 weeks at birth (near the time point of the definition of BPD and when many healthy preterms are nearing discharge); (2) no clinical respiratory distress i.e., no need for continuous positive airway pressure (CPAP) and no need for supplemental oxygen; (3) studied within $96 \mathrm{~h}$ of age. These patients were matched for race and gender to the study group of patients with BPD. We excluded patients with a history of oligohydramnios, concern for pulmonary hypoplasia or major congenital anomalies, chromosomal abnormalities, and multiple gestation greater than twins. Gestational age was defined according to the date of the mother's last menstrual period (if known and reliable) or by ultrasound if done before 20 weeks of pregnancy.

\section{Study endpoints}

The primary outcome of our study was comparison of FRC between the two groups. We also compared $\mathrm{Crs}$ and respiratory system resistance (Rrs) in the two groups of patients as secondary outcomes, and monitored other pertinent clinical respiratory parameters.

\section{Measurements}

Infant PFTs were measured with a computerized infant pulmonary function cart (SensorMedics 2600, SensorMedics Inc., Yorba Linda, California). No sedation was used for testing. FRC was measured with the nitrogen washout method, and Crs and Rrs with the single-breath occlusion technique [6, 8-12]. These measurements can be performed in non-intubated and intubated infants.

For the nitrogen washout method [8-10], calibration was performed with two known volumes, and a calibration line was constructed for the system at the specific flow rate. The calibration curve was then used to correlate the nitrogen washed out to the infant's FRC. The system corrected for dead space present and corrected the FRC to body temperature, pressure, and water-saturated conditions. Total FRC was related to body weight. Acceptance criteria as per the American Thoracic Society and European Respiratory Society included: (1) infant supine and quietly asleep, (2) test initiated at end-expiration, (3) no evidence of leak on tracing of the washout, (4) consistent tracings, and (5) at least three measurements with a coefficient of variation $<10 \%$ [13].

Crs was measured with the single-breath occlusion technique [11, 14, 15] while the patient was supine and quietly asleep. During this test, the airway was briefly occluded at end inspiration until an airway pressure plateau was observed, invoking the Hering Breuer reflex. Crs and respiratory resistance were calculated from the passive flowvolume curve and total Crs was related to body weight. Acceptance criteria included: (1) stable end-expiratory baseline, (2) plateau pressure lasting $>100 \mathrm{~ms}$, (3) plateau pressure varying by $< \pm 0.125-\mathrm{cm} \mathrm{H}_{2} \mathrm{O}$, (4) acceptable flowvolume curve by visual inspection, with linear data segment identified, and (5) at least 10 breaths accepted with a coefficient of variation $<20 \%[11,14,15]$.

Clinical respiratory parameters including need for surfactant administration, days of mechanical ventilation, days on oxygen supplementation were also monitored. Surfactant was given to newborn infants with moderate to severe respiratory distress syndrome. If needed, surfactant was administered within the first $24 \mathrm{~h}$ of life if the patient required $>0.40 \mathrm{FiO}_{2}$ to maintain adequate $\mathrm{SpO}_{2}$, had a $\mathrm{pH}<7.25$, and/or had increased work of breathing despite adequate CPAP. In addition, oxygen supplementation was initiated if the $\mathrm{SpO}_{2}$ was lower than $90 \%$ in our BPD patients.

\section{Statistical analyses}

From our published data in healthy late preterm infants (33-36 weeks' gestation) [8] with an average FRC of 
$24.6 \mathrm{~mL} / \mathrm{kg} \pm \mathrm{SD}$ of 5.1 , for the current study, we estimated a sample size of $\sim 20$ patients in each group to detect a difference in FRC equivalent to at least one standard deviation of the measurement with $80 \%$ power and a type I error of 0.05 .

Differences in continuous variables, including PFTs between the two groups, were analyzed by two-tailed, Student's $t$ tests. Mann-Whitney $U$ test was used where appropriate (for data not normally distributed). Categorical variables were evaluated with Chi-Square tests and Fisher's exact test where appropriate. Data are expressed as mean \pm $\mathrm{SD}$, unless otherwise indicated.

We matched 20 healthy infants born at 34-36 weeks for gender and race to the 20 ELBW infants with BPD in the study group. This approach increased the homogeneity between both groups. Mixed linear modeling [16] was used to compare FRC/kg and total FRC in both groups (primary outcome). Mixed linear modeling for continuous variables was also used to compare differences in other PFTs (secondary outcomes) between the groups. This approach accounts for the correlation between twins and allows for adjustment for additional covariates and potential confounders [16]. Our model included the important covariates of study weight, postmenstrual age at study, and twin gestation. Other potential covariates included in the analyses were race, gender, and length at study. We used SPSS for Windows, version 22.0 (SPSS Inc, Chicago, Illinois) and SAS, version 9.4 (SAS Institute Inc, Cary, North Carolina) for analyses.

\section{Results}

We concurrently studied 20 ELBW infants with BPD and 20 healthy late preterm infants (born at 34-36 weeks) matched to the study group for gender and race. Maternal and infant demographics are shown in Table 1. The BPD study group included three sets of twins and the comparison group of healthy infants included one set of twins. BPD patients had a mean birth weight of $788 \mathrm{~g}$ and gestational age of 25.8 weeks, with $50 \%$ female, and $95 \%$ Caucasian. The healthy infants had a birth weight of $2389 \mathrm{~g}$, gestational age of 34.5 weeks with the same gender and race distribution as the patients with BPD. Ninety percent of the ELBW infants with BPD received antenatal steroids versus $45 \%$ in the comparison group of healthy late preterm infants (Table 1).

\section{Clinical characteristics of study groups}

BPD patients were studied at a median of 36.0 weeks postmenstrual age versus 34.9 weeks in the healthy infants.
Table 1 Maternal and infant demographics/clinical characteristics.

\begin{tabular}{|c|c|c|c|}
\hline & $\begin{array}{l}\text { BPD } \\
(n=20)\end{array}$ & $\begin{array}{l}\text { No BPD } \\
(n=20)\end{array}$ & $P$ \\
\hline Maternal age (years) ${ }^{\mathrm{a}}$ & $26.7 \pm 7.1$ & $25.7 \pm 6.6$ & NS \\
\hline Preterm labor (\%) & $17(85)$ & $11(55)$ & $<0.05$ \\
\hline $\begin{array}{l}\text { Hypertension/ } \\
\text { preeclampsia (\%) }\end{array}$ & $1(5)$ & $4(20)$ & NS \\
\hline Antepartum hemorrhage (\%) & $4(20)$ & $0(0)$ & $<0.05$ \\
\hline Maternal smoking $(\%)^{\mathrm{b}}$ & $5(28)$ & $4(21)$ & NS \\
\hline $\begin{array}{l}\text { Small for gestational age } \\
(\%)^{\mathrm{c}}\end{array}$ & $1(5)$ & $1(5)$ & NS \\
\hline $\operatorname{ROM}(\mathrm{h})^{\mathrm{d}}$ & $0(0-1)$ & $0.9(0-14)$ & NS \\
\hline $\mathrm{ROM}>24 \mathrm{~h}(\%)$ & $5(25)$ & $4(20)$ & NS \\
\hline Cesarean section (\%) & $15(75)$ & $9(45)$ & NS \\
\hline $\begin{array}{l}\text { Gestational age at birth } \\
(\text { weeks) }\end{array}$ & $25.8 \pm 1.3$ & $34.5 \pm 0.6$ & $<0.05$ \\
\hline Birth weight $(\mathrm{g})^{\mathrm{a}}$ & $788 \pm 138$ & $2389 \pm 318$ & $<0.05$ \\
\hline Caucasian $(\%)$ & $19(95)$ & $19(95)$ & NS \\
\hline Female $(\%)$ & $10(50)$ & $10(50)$ & NS \\
\hline 1-min Apgar ${ }^{\mathrm{d}}$ & $5(3-6)$ & $8(6-8)$ & $<0.05$ \\
\hline 5-min Apgar ${ }^{d}$ & $7(6-8)$ & $8(8-9)$ & $<0.05$ \\
\hline Antenatal steroids (\%) & $18(90)$ & $9(45)$ & $<0.05$ \\
\hline Surfactant (\%) & $19(95)$ & $0(0)$ & $<0.05$ \\
\hline Study weight $(\mathrm{g})^{\mathrm{a}}$ & $2240 \pm 512$ & $2390 \pm 318$ & NS \\
\hline PMA at study (weeks) ${ }^{d}$ & $36.0(35.0-37.4)$ & $34.9(34.5-35.3)$ & $<0.05$ \\
\hline Study length $(\mathrm{cm})^{\mathrm{a}}$ & $42.8 \pm 3.0$ & $46.3 \pm 1.6$ & $<0.05$ \\
\hline $\begin{array}{l}\text { Mechanical ventilation } \\
\text { (days) }^{\mathrm{d}}\end{array}$ & $30.3(12.5-42.8)$ & 0 & \\
\hline $\begin{array}{l}\text { Oxygen supplementation } \\
\text { (days) }^{\mathrm{d}}\end{array}$ & $95.5(78.2-120.5)$ & 0 & \\
\hline
\end{tabular}

The BPD group included three sets of twins and the comparison group of healthy infants included one set of twins (NS).

$B P D$ bronchopulmonary dysplasia, $R O M$ rupture of membranes, $P M A$ postmenstrual age, $N S$ not significant.

${ }^{\mathrm{a}}$ Mean \pm SD.

${ }^{\mathrm{b}}$ Data available for 18 versus 19 patients.

${ }^{\mathrm{c}}$ Birth weight $<10$ th percentile.

${ }^{\mathrm{d}}$ Median (25th-75th percentiles).

Four infants with BPD were studied at 37-38 weeks because of difficulty in completing the PFTs by 36 weeks. Their average study weights were 2240 versus $2390 \mathrm{~g}$, respectively. There was a significant difference in mean body length at the time of study at 42.8 versus $46.3 \mathrm{~cm}$ (Table 1). Our patients with moderate/severe BPD [1] were on mechanical ventilation for a median of 30.3 days, and 10 of the 20 patients weaned off oxygen while in the NICU with a median duration of oxygen supplementation of 95.5 days (Table 1). The four BPD infants on mechanical ventilation at the time of PFTs were studied on a positive end-expiratory pressure of $5-\mathrm{cm}_{2} \mathrm{O}$. All patients were discharged from the NICU, ten patients with BPD were discharged on low flow nasal cannula oxygen. None of the patients required a tracheostomy or medications for pulmonary hypertension. 


\section{Primary outcome}

ELBW infants with BPD in the study group had significantly decreased FRC normalized for body weight $(\mathrm{FRC} / \mathrm{kg}$ ) and total FRC when compared to healthy infants born at 34-36 weeks (Table 2). These differences remained significant after accounting for the correlation (nonindependence) between twins, and using mixed linear modeling to adjust for the confounding variables of study weight, postmenstrual age at study, and twin gestation. The mean FRC normalized per $\mathrm{kg}$ in the BPD group was $28 \%$ lower than in the comparison group of healthy infants: 18.9 versus $26.2 \mathrm{~mL} / \mathrm{kg}$ (adjusted 95\% CI for difference 5.0 , $10.9 ; P<0.001$ ). (Table 2). Mixed linear modeling showed that the variables of race, gender, and length at study were not statistically significant when added to the model.

\section{Secondary outcomes}

Secondary outcomes were compared accounting for the correlation between twins, and using mixed linear modeling (continuous variables) to adjust for the potential confounders of study weight, postmenstrual age at study, and twin gestation. Patients with BPD had a significantly decreased respiratory compliance normalized for body weight or $\mathrm{Crs} / \mathrm{kg}$ ( 0.80 versus $1.29-\mathrm{mL} / \mathrm{cm} \mathrm{H}_{2} \mathrm{O} / \mathrm{kg}$; adjusted $P$ value $<0.001)$ and total $\mathrm{Crs}$ when compared to healthy infants in the comparison group (Table 2). Respiratory resistance was increased in infants with BPD compared to healthy infants (adjusted $P$ value $<0.001$ ). Specific compliance, which is Crs normalized for lung volume/FRC (Crs/FRC), was not significantly different between the groups. However, our study was not powered for differences in secondary outcomes.

\section{Discussion}

In this study, we demonstrated that ELBW infants with BPD studied at 34-36 weeks of postmenstrual age have decreased pulmonary function compared to healthy infants delivered at 34-36 weeks. Both FRC and Crs were significantly decreased in these patients with contemporary BPD. Our findings suggest that infants with BPD have smaller lung volumes, and we speculate that this is due to impaired alveolarization. This provides physiologic evidence that efforts to prevent or mitigate BPD should likely focus on therapies to improve lung growth.

There are a number of longitudinal pulmonary function studies [17-19] demonstrating that individuals follow along a pulmonary function percentile that is established early in life, therefore emphasizing the importance of quantification of early life PFTs. There are several factors that can affect

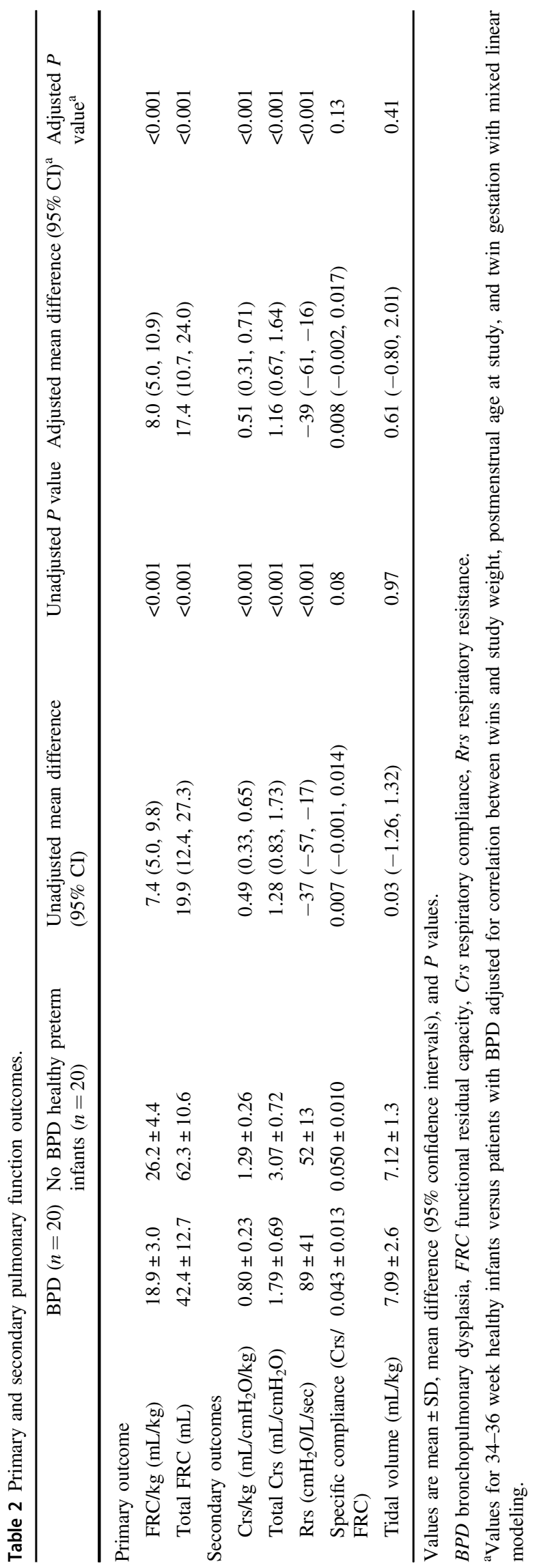


lung development and influence an individual's placement on the PFT curve including in-utero factors such as in-utero smoke [20, 21] or intrauterine growth restriction [22], but preterm delivery is the most common cause of altered lung development $[22,23]$. The application of PFTs has been important in quantifying the physiologic effects of several successful neonatal interventions such as antenatal steroids [24] and postnatal surfactant [25]. Early life PFTs are also important to understand the development of BPD if early interventions are to be developed for primary intervention. A longitudinal study [26] demonstrated that Crs was 50\% of predicted during the early phase of BPD and was associated with abnormal Rrs values. These values normalized over the first 2 years of life but significant airway dysfunction persisted in many infants [26]. This illustrates the importance of defining the trajectory of the "healthy" premature lung for an appropriate comparison or control for infants at risk for or diagnosed with BPD [5].

We demonstrated in this cohort that ELBW infants with contemporary BPD have a significantly decreased FRC and Crs compared to matched healthy preterm infants (mean gestational age at birth 34.5 weeks), when both groups are studied at 34-36 weeks postmenstrual age. This supports the findings of a previous study in 2005 by Hjalmarson and Sandberg [27] of decreased FRC at term-corrected age in infants born at $<31$ weeks of gestation who developed BPD, compared to healthy preterm infants without signs of respiratory distress or need for extra oxygen after 2 days of age ( $n=19$, mean gestational age 29 weeks) who did not develop BPD. Our BPD population is more contemporary with $90 \%$ receiving antenatal steroids (compared to about $32 \%$ of their population), $95 \%$ received surfactant, and all infants had a birth weight of $<1000 \mathrm{~g}$ with a mean gestational age of 25.8 weeks. We also have a more mature "healthy" preterm reference/control group and performed PFTs at a slightly lower postmenstrual age. However, both studies clearly show a decrease in FRC in infants with BPD regardless of the reference group (our subjects met the criteria of moderate or severe BPD [1] at the time of PFTs). We found a significantly decreased Crs in the patients with BPD. However, the specific compliance (Crs/FRC) was not significantly different between groups (adjusted $P$ value 0.13). Our study was not powered for the outcomes of Crs or specific Crs so it is difficult to determine if the elastic properties of the lungs were significantly decreased in our population. In infants with BPD, there are fewer and larger alveoli and less tethering of the airways through the elastic components in alveolar walls, which can affect elastic recoil $[28,29]$. Our data seem to support that most of the change in Crs was due to changes in lung volume/FRC however a larger sample size may have allowed us to demonstrate a difference in both FRC and specific compliance between the groups. Other studies have shown a decreased Crs in infants with BPD [26]. In addition, it is difficult to determine the most appropriate comparison group since healthy preterm infants have been shown to have altered lung mechanics at term $[8,30]$, even without having clinical lung disease, and as a group progress to greater wheezing and asthma than term infants [31].

In this cohort we demonstrated that ELBW infants with BPD had increased Rrs compared to healthy preterm infants born at a mean gestational age of 34.5 weeks. The Rrs of our patients with $\mathrm{BPD}$ was $89-\mathrm{cm} \mathrm{H}_{2} \mathrm{O} / \mathrm{L} / \mathrm{s}$, which was very similar to the Rrs described in infants with BPD in other studies [27], while the Rrs of our healthy preterm controls was $52-\mathrm{cm} \mathrm{H}_{2} \mathrm{O} / \mathrm{L} / \mathrm{s}$. The technique we used to measure passive respiratory mechanics primarily measures the Rrs of the central aiways, but aligns nicely with the recent study of Shepherd et al. [6], who measured forced expiratory flows (FEFs) in 56 former preterm infants with severe BPD at a median of 52 weeks of postmenstrual age and identified that $51 \%$ of these infants had obstructive, $40 \%$ had mixed, and $9 \%$ had restrictive infant PFT phenotypes. Studies of former preterm infants with BPD have demonstrated increased measures of airflow obstruction with decreased FEFs in childhood and adolescence compared to term controls with associated increased incidence of wheeze and asthma [32-34].

There are several limitations to our study. Our sample size is small, however neonatal PFTs in the NICU are a sophisticated measurement, and we met our desired sample size matched for gender and race to demonstrate a significant difference of one standard deviation in FRC between the groups. We did not measure all infants with BPD consecutively so bias may have been introduced, but our FRC measurements in infants with BPD are comparable to those of previous studies [27]. For a direct comparison to other studies measuring FEFs as a measure of peripheral airway obstruction in infants with BPD, performance of the raised volume rapid thoracic compression technique would have been required [35], but we were limited by patient size for this equipment. We have also previously reported in 40 very low birth weight infants studied at 35 weeks postmenstrual age that over 50\% respond to albuterol [36]. However, we did not consistently perform pre- and post-bronchodilator tests in our current cohort of infants with BPD, which may have helped to further define their phenotype.

In conclusion, ELBW infants with BPD when studied at 34-36 weeks of postmenstrual age have a significantly decreased FRC/lung volume when compared to healthy preterm infants delivered at 34-36 weeks of gestation and studied within the first $96 \mathrm{~h}$ of life. Respiratory compliance was also decreased in patients with BPD. This further supports the premise that contemporary BPD is a disease of impaired alveolarization and continued research into interventions to promote lung growth [37, 38] is needed to prevent and/or mitigate BPD. 
Acknowledgements The authors would like to thank the neonatologists, obstetricians, neonatal fellows, and the staff of our Neonatal Intensive Care Unit for their help with the study.

Author contributions Drafting the manuscript: all authors; data analysis: SM.

Funding Supported by NIH/NHLBI (K23 HL080231 and R01 HL105447), Office of Dietary Supplements to CTM.

\section{Compliance with ethical standards}

Conflict of interest The authors declare that they have no conflict of interest.

Publisher's note Springer Nature remains neutral with regard to jurisdictional claims in published maps and institutional affiliations.

\section{References}

1. Jobe AH, Bancalari E. Bronchopulmonary dysplasia. Am J Respir Crit Care Med. 2001;163:1723-9.

2. Northway WH Jr, Rosan RC, Porter DY. Pulmonary disease following respirator therapy of hyaline-membrane disease. Bronchopulmonary dysplasia. N Engl J Med. 1967;276:357-68.

3. Baraldi E, Filippone M. Chronic lung disease after premature birth. N Engl J Med. 2007;357:1946-55.

4. Coalson JJ. Pathology of bronchopulmonary dysplasia. Semin Perinatol. 2006;30:179-84.

5. McEvoy CT, Jain L, Schmidt B, Abman S, Bancalari E, Aschner JL. Bronchopulmonary dysplasia: NHLBI Workshop on the Primary Prevention of Chronic Lung Diseases. Ann Am Thorac Soc. 2014;11:S146-53.

6. Shepherd EG, Clouse BJ, Hasenstab KA, Sitaram S, Malleske DT, Nelin LD, et al. Infant pulmonary function testing and phenotypes in severe bronchopulmonary dysplasia. Pediatrics. 2018;141: e20173350.

7. Doyle LW, Faber B, Callanan C, Freezer N, Ford GW, Davis NM. Bronchopulmonary dysplasia in very low birth weight subjects and lung function in late adolescence. Pediatrics. 2006;118: 108-13.

8. McEvoy C, Venigalla S, Schilling D, Clay N, Spitale P, Nguyen T. Respiratory function in healthy late preterm infants delivered at 33-36 weeks of gestation. J Pediatr. 2013;162:464-9.

9. Yuksel B, Greenough A, Chan V, Russell RR. Comparison of helium dilution and nitrogen washout measurements of functional residual capacity in premature infants. Pediatr Pulmonol. 1993;16: 197-200.

10. Gerhardt T, Hehre D, Bancalari E, Watson H. A simple method for measuring functional residual capacity by $\mathrm{N} 2$ washout in small animals and newborn infants. Pediatr Res. 1985;19:1165-9.

11. Gappa M, Colin AA, Goetz I, Stocks J. Passive respiratory mechanics: the occlusion techniques. Eur Respir J. 2001;17: $141-8$

12. Go M, Schilling D, Nguyen T, Durand M, McEvoy CT. Respiratory compliance in late preterm infants $\left(34^{0 / 7}-34^{6 / 7}\right.$ weeks $)$ after antenatal steroid therapy. J Pediatr. 2018;201:21-26.

13. Morris MG, Gustafsson P, Tepper R, Gappa M, Stocks J. The bias flow nitrogen washout technique for measuring the functional residual capacity in infants. ERS/ATS Task Force on Standards for Infant Respiratory Function Testing. Eur Respir J. 2001;17:529-36.
14. McEvoy C, Schilling D, Spitale P, Peters D, O’Malley J, Durand $M$. Decreased respiratory compliance in infants less than or equal to 32 weeks' gestation, delivered more than 7 days after antenatal steroid therapy. Pediatrics. 2008;121:e1032-8.

15. McEvoy CT, Schilling D, Clay N, Jackson K, Go MD, Spitale P, et al. Vitamin $\mathrm{C}$ supplementation for pregnant smoking women and pulmonary function in their newborn infants: a randomized clinical trial. JAMA. 2014;311:2074-82.

16. Brown H, Prescott R. Applied mixed models in medicine. Chichester, United Kingdom: John Wiley and Sons; 2003.

17. Friedrich L, Pitrez PM, Stein RT, Goldani M, Tepper R, Jones $\mathrm{MH}$. Growth rate of lung function in healthy preterm infants. Am J Respir Crit Care Med. 2007;176:1269-73.

18. Martinez FJ, Han MK, Allinson JP, Barr RG, Boucher RC, Calverley PMA, et al. At the root: defining and halting progression of early chronic obstructive pulmonary disease. Am J Respir Crit Care Med. 2018;197:1540-51.

19. Stern DA, Morgan WJ, Wright AL, Guerra S, Martinez FD. Poor airway function in early infancy and lung function by age 22 years: a non-selective longitudinal cohort study. Lancet. 2007; 370:758-64

20. McEvoy CT, Shorey-Kendrick LE, Milner K, Schilling D, Tiller C, Vuylsteke B, et al. Oral vitamin C (500 mg/day) to pregnant smokers improves infant airway function at 3 months (VCSIP): a randomized trial. Am J Respir Crit Care Med. 2019;199:1139-47.

21. Morrow LA, Wagner BD, Ingram DA, Poindexter BB, Schibler $\mathrm{K}$, Cotton CM, et al. Antenatal determinants of bronchopulmonary dysplasia and late respiratory disease in preterm infants. Am J Respir Crit Care Med. 2017;196:364-74.

22. Stocks J, Hislop A, Sonnappa S. Early lung development: lifelong effect on respiratory health and disease. Lancet Respir Med. $2013 ; 1: 728-42$.

23. Kotecha SJ, Edwards MO, Watkins WJ, Henderson AJ, Paranjothy S, Dunstan FD, et al. Effect of preterm birth on later FEV1: a systematic review and meta-analysis. Thorax. 2013;68:760-6.

24. McEvoy C, Schilling D, Peters D, Tillotson C, Spitale P, Wallen $\mathrm{L}$, et al. Respiratory compliance in preterm infants after a single rescue course of antenatal steroids: a randomized controlled trial. Am J Obstet Gynecol. 2010;202:544.e1-544.e9.

25. Dinger J, Topfer A, Schaller P, Schwarze R. Functional residual capacity and compliance of the respiratory system after surfactant treatment in premature infants with severe respiratory distress syndrome. Eur J Pediatr. 2002;161:485-90.

26. Baraldi E, Filippone M, Trevisanuto D, Zanardo V, Zacchello F. Pulmonary function until two years of life in infants with bronchopulmonary dysplasia. Am J Respir Crit Care Med. 1997;155:149-55

27. Hjalmarson O, Sandberg KL. Lung function at term reflects severity of bronchopulmonary dysplasia. J Pediatr. 2005;146: 86-90.

28. Plopper CG, Nishio SJ, Schelegle ES. Tethering tracheobronchial airways within the lungs. Am J Respir Crit Care Med. 2003;167: $2-3$.

29. Colin AA, McEvoy C, Castile RG. Respiratory morbidity and lung function in preterm infants of 32 to 36 weeks' gestational age. Pediatrics. 2010;126:115-28.

30. Hjalmarson O, Sandberg K. Abnormal lung function in healthy preterm infants. Am J Respir Crit Care Med. 2002;165:83-7.

31. Goyal NK, Fiks AG, Lorch SA. Association of late-preterm birth with asthma in young children: practice based study. Pediatrics. 2011;128:e830-8.

32. Doyle LW, Ford GW, Olinsky A, Knoches AM, Callanan C. Bronchopulmonary dysplasia and very low birthweight: lung function at 11 years of age. J Paediatr Child Health. 1996;32: $339-43$. 
33. Doyle LW. Respiratory function at age 8-9 years in extremely low birthweight/very preterm children born in Victoria in 1991-1992. Pediatr Pulmonol. 2006;41:570-6.

34. Korhonen P, Laitinen J, Hyodynmaa E, Tammela O. Respiratory outcome in school-aged, very-low-birth-weight children in the surfactant era. Acta Paediatr. 2004;93:316-21.

35. Jones MH, Davis SD, Grant D, Christoph K, Kisling J, Tepper RS. Forced expiratory maneuvers in very young children. Assessment of flow limitation. Am J Respir Crit Care Med. 1999; 159:791-5.
36. Morrow DK, Schilling D, McEvoy CT. Response to bronchodilators in very preterm infants with evolving bronchopulmonary dysplasia. Res Rep Neonatol. 2015;5:113-7.

37. Lam R, Schilling D, Scottoline B, Platteau A, Niederhausen M, Lund $\mathrm{KC}$, et al. The effect of extended continuous positive airway pressure on changes in lung volumes in stable premature infants: a randomized controlled trial. J Pediatr. 2020;217:66-72.e1.

38. Thebaud B. Mesenchymal stromal cell therapy for respiratory complications of extreme prematurity. Am J Perinatol. 2018;35: $566-9$. 